\title{
The full-SiC optics of MICROCARB
}

Michel Bougoin, Florent Mallet, Jérôme Lavenac, Guillaume Gaudé, Olivier Martin

Michel Bougoin, Florent Mallet, Jérôme Lavenac, Guillaume Gaudé, Olivier Martin, "The full-SiC optics of MICROCARB," Proc. SPIE 11852, International Conference on Space Optics - ICSO 2020, 118524K (11 June 2021); doi: $10.1117 / 12.2599665$

SPIE Event: International Conference on Space Optics - ICSO 2021, 2021, Online Only 


\section{International Conference on Space Optics-ICSO 2020}

Virtual Conference

30 March-2 April 2021

Edited by Bruno Cugny, Zoran Sodnik, and Nikos Karafolas
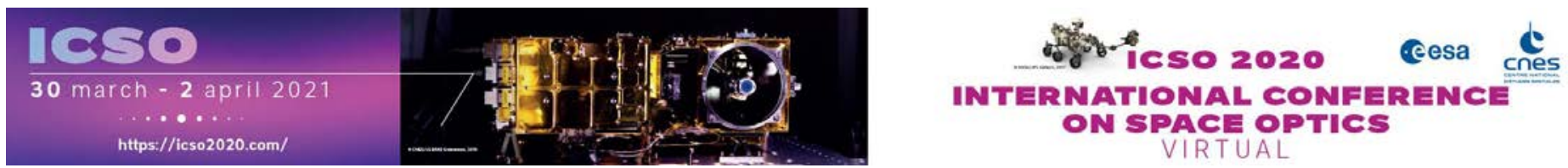

The full-SiC optics of MICROCARB

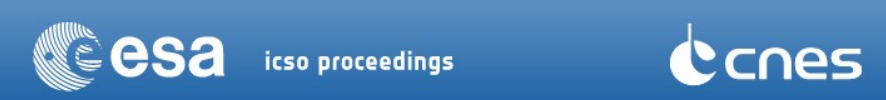

International Conference on Space Optics - ICSO 2020, edited by Bruno Cugny, Zoran Sodnik, Nikos Karafolas, Proc. of SPIE Vol. 11852, 118524K · @ 2021 ESA and CNES

CCC code: $0277-786 \mathrm{X} / 21 / \$ 21 \cdot$ doi: $10.1117 / 12.2599665$ 


\title{
The full-SiC optics of MICROCARB
}

\author{
Michel Bougoin*a, Florent Mallet ${ }^{\mathrm{a}}$, Jérôme Lavenac ${ }^{\mathrm{a}}$, Guillaume Gaudéb, Olivier Martin ${ }^{\mathrm{b}}$ \\ ${ }^{a}$ Mersen Boostec, ZAE Ceram'Innov Pyrénées, 65460 Bazet, France; \\ ${ }^{b}$ Airbus Defence and Space, 31 Avenue des Cosmonautes, 31402 Toulouse, France
}

\begin{abstract}
To be launched in 2022, MicroCarb is a space mission project of the French Space Agency (CNES) that will measure the exchange of carbon dioxide present in the Earth's atmosphere over all regions of the globe, particularly in areas poorly covered by terrestrial instrumentation. It will be the first European mission entirely dedicated to $\mathrm{CO}_{2}$ measurement. Airbus Defence and Space has been selected by CNES to design, develop and qualify the MicroCarb instrument able to monitor very precisely $\mathrm{CO}_{2}$ concentrations, with an accuracy better than 1 part per million. It is an infrared passive spectrometer operating in four spectral bands and including a unique imaging channel.

To meet the need for unprecedented stability, Airbus Defence and Space turned to a full-SiC solution for the mirrors and the structural elements of the instrument. These optics are embarked on the Myriades microsat platform which allocates them a low volume. This led the designers to squeeze the instruments into a compact volume and thus to design complex three-dimensional structures and also to implement mirrors of high freeform amplitudes.

The present paper presents the manufacturing approach for such highly complex silicon carbide (SiC) parts, especially the grinding of complex interfaces and very precise freeform mirror blanks ready for polishing.

Keywords: space optics, freeform optics, silicon carbide, MicroCarb, SiC mirror, SiC structure, thermomechanical stability, precise grinding

\section{INTRODUCTION}

When designing MicroCarb's optics, Airbus Defence and Space had to face two challenges: the need for unprecedented thermomechanical stability and a very low volume allocation. Thanks to their extensive experience with Boostec ${ }^{\mathbb{B}} \mathrm{SiC}_{\text {, }}$ this naturally led the designers to full-SiC optics but also to highly innovative freeform mirrors. For Mersen Boostec, this required the development of innovative processes, especially for the finishing of the required SiC parts, which are very complex, in three dimensions and precise in shape. Microcarb instrument includes a pointing mirror, two Three-Mirror Anastigmat (TMA) telescopes, three folding mirrors, a reflection grating substrate and a large radiator plate, all fully designed in Boostec ${ }^{\mathbb{R}} \mathrm{SiC}$ material.
\end{abstract}

\section{BOOSTEC ${ }^{\circledR}$ SiC MATERIAL FOR SPACE OPTICS}

For space optics, the key properties of $\mathbf{B o o s t e c}^{\circledR} \mathrm{SiC}$ material are its high specific stiffness $\left(420 \mathrm{GPa} / 3.15 \mathrm{~g} . \mathrm{cm}^{-3}\right)$ combined with its high thermal stability $\left(180 \mathrm{~W} \cdot \mathrm{m}^{-1} \cdot \mathrm{K}^{-1} / 2.2 \cdot 10^{-6} \mathrm{~K}^{-1}\right)$.

Its high mechanical strength allows making mirrors but also structural parts, such as the structures of the two MicroCarb TMA telescopes.

Thanks to its isotropic microstructure, the physical properties of this alpha type $\mathrm{SiC}$ are perfectly isotropic and reproducible inside a same large part or from batch to batch. In particular, no Coefficient of Thermal Expansion (CTE) mismatch has been measurable, with accuracy in the range of $10^{-9} \mathrm{~K}^{-1}$ [1]. The CTE of Boostec ${ }^{\mathbb{B}} \mathrm{SiC}$ is decreasing from 2.2.10 $0^{-6} \mathrm{~K}^{-1} @$ room temperature down to $0.2 .10^{-6} \mathrm{~K}^{-1} @ 100 \mathrm{~K}$ and close to zero between 0 and 35K. Its thermal conductivity remains over $150 \mathrm{~W} / \mathrm{m} . \mathrm{K}$ in the $70 \mathrm{~K}-360 \mathrm{~K}$ temperature range.

This material shows no mechanical fatigue, no outgassing and no absorption or release of moisture. It has been fully qualified for space application at cryogenic temperatures.

*michel.bougoin@mersen.com; boostec@mersen.com; www.mersen.com 
Although perfectly tight, Boostec ${ }^{\circledR} \mathrm{SiC}$ material exhibits a $<2.5$ vol.\% residual porosity which leads to unacceptable level of stray light, particularly for visible and UV range application. This is the reason why the mirrors optical face is generally coated with a pore-free SiC layer obtained by Chemical Vapor Deposition (CVD) or another alternative polishing layer, as it is the case for all MicroCarb optics.

Since 2004, 20 full-SiC telescopes made of this technical ceramic are (or have been) successfully operating in space, including Rosetta Osiris Narrow Angle Camera (NAC), Herschel and Gaia [2] [3] for science purpose together with Sentinel-2 Multi Spectral Instruments and a lot of Korsch ones dedicated to earth observation [4]. We must also mention the Euclid full-SiC telescope and its instruments VIS and NISP [5] [6], the structures of which are made of Boostec ${ }^{\circledR}$ SiC material, to be launched mid-2022; it is now fully integrated and submitted to final tests.

\begin{tabular}{ll} 
Table 1. Basic Properties of Boostec ${ }^{\circledR} \mathrm{SiC}$ & \\
\hline Properties & Typical Values @ 293 K \\
\hline Density & $3.15 \mathrm{~g} \cdot \mathrm{cm}^{-3}$ \\
Young's modulus & $420 \mathrm{GPa}$ \\
Bending strength / Weibull modulus (coaxial double ring bending test) & $400 \mathrm{MPa} / 11$ \\
Poisson's ratio & 0.17 \\
Toughness $\left(\mathrm{K}_{1 \mathrm{C}}\right)$ & $4.0 \mathrm{MPa} \cdot \mathrm{m}^{1 / 2}$ \\
Coefficient of Thermal Expansion (CTE) & $2.2 .10^{-6} \mathrm{~K}^{-1}$ \\
Thermal Conductivity & $180 \mathrm{~W} \cdot \mathrm{m}^{-1} \cdot \mathrm{K}^{-1}$ \\
Electrical Conductivity & $10^{5} \Omega \cdot \mathrm{m}$ \\
\end{tabular}

\section{MICROCARB}

\subsection{The MicroCarb mission}

Decided in the context of the COP21 climate conference, MicroCarb is a CNES microsatellite mission to be launched in 2022 with the goal to monitor the fluxes of carbon dioxide $\left(\mathrm{CO}_{2}\right)$ at the surface between the atmosphere and the oceans and vegetation. A better knowledge of the carbon flux is needed to [7] [8]:

- Understand the functioning of the vegetation (yearly cycle, response to meteorological anomalies),

- Identify and quantify the terrestrial ecosystem Carbon sinks and sources at yearly scales (where are the Carbon sinks/sources; how do they evolve with the climate changes),

- Quantify the oceanic Carbon sources and sinks at yearly scales and their responses to the announced climate changes,

- Contribute to the measurement of Carbon emission linked to fossil fuels use.

Carrying a more compact instrument, almost three times lighter than its predecessor onboard OCO-2, MicroCarb is built around a microsatellite bus developed by CNES and stemming from the Myriade system; it will enable local measurements of $\mathrm{CO}_{2}$ concentrations in areas of intense human activity. MicroCarb will be the first European mission entirely dedicated to $\mathrm{CO}_{2}$ measurement.

\subsection{The MicroCarb instrument}

Airbus Defence and Space has been selected by the French Agency for the design and the development of the MicroCarb instrument, able to monitor very precisely greenhouse gases concentration in the atmosphere through passive sounding thanks to a very compact spectrometer, offering probationary capabilities to prepare next generation satellites (spectral imagery capability). From 2022 onwards, MicroCarb will be able to measure the $\mathrm{CO}_{2}$ content over the entire atmospheric column with a high degree of accuracy, of the order of $1 \mathrm{ppm}$, and with a pixel size of $4.5 \mathrm{~km} \mathrm{x} 9.0 \mathrm{~km}$.

The baseline instrument includes four spectral bands (Table 2) and an imaging channel. The instrument optical overview presented below shows:

- The pointing mirror at the instrument entrance port, allowing the across track pointing function, the along track pointing for sun glint monitoring being performed by the spacecraft AOCS.

- The polarization scrambler, the pupil mask and the pupil separation prisms, placed close to the telescope entrance pupil plane. 
- The entrance telescope, including a field stop at the primary mirror intermediate focal plane, the folding mirror in the exit pupil allowing separation between the sounding channels and the imaging channel. The array used for the imaging channel is placed in the telescope focal plane.

- The cryostat anti-contamination window in front on the slit and pupil alignment prisms assembly.

- The TMA spectrometer operating in near-Littrow configuration, with the echelle grating in the pupil plane.

- The band pass filter assembly and the detector array.

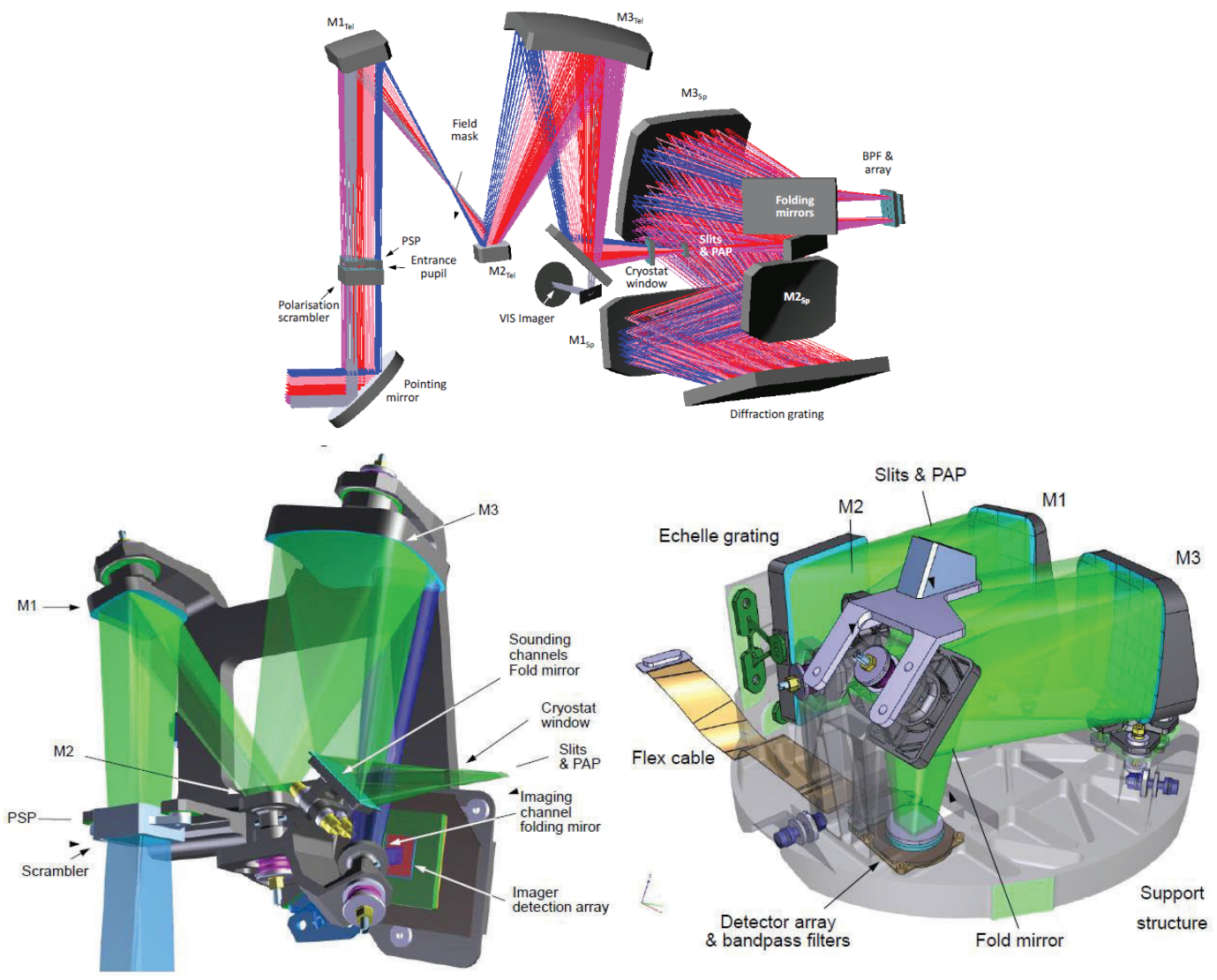

Figure 1. Baseline instrument optical layout and accommodation [9].

The main design drivers of the MicroCarb instrument are exhibited on following Table 2 .

Table 2. Design drivers of MicroCarb instrument

\begin{tabular}{ll}
\hline Mass & $<80 \mathrm{~kg}$ \\
$\mathrm{CO}_{2}$ concentration accuracy & $<1 \mathrm{ppm}$ \\
\hline Acquisition of 4 spectral bands with a single instrument & $763.5 \mathrm{~nm} \quad 1273.4 \mathrm{~nm}$ \\
& $1607.9 \mathrm{~nm} 2037.1 \mathrm{~nm}$ \\
Operating temperature & Telescope optics@, 293 K \\
(passive cooling) & Spectrometer optics @, 220K \\
Detector & Detector array @ 150 K \\
\hline Power & NGP Lynred \\
\hline
\end{tabular}


The optics and structural elements of both telescopes are made of silicon carbide; this full-SiC technology provides highly stable instruments; this is especially mandatory for the spectrometer section which requires unprecedented thermoelastic stability in order to guaranty the in-orbit accurate knowledge of the instrument spectral response function [9].

\section{THE SIC PARTS}

\subsection{Co-engineering}

The SiC parts have been designed by Airbus Defence and Space with the assistance of Mersen Boostec team to ensure better feasibility, mitigate risks and also reduce costs and lead time.

The following parts were designed in Boostec ${ }^{\circledR} \mathrm{SiC}$ material: the Pointing mirror (PCS, in Figure 2), the two ThreeMirror Anastigmat (TMA) telescopes, the three folding mirrors, the reflection grating substrate and the large radiator plate.

The main challenge was to deal with the low volumes allocated by the Myriade platform. It led the designers to create structures with very complex shapes; the same goes for the mirror fixtures sometimes requiring complicated forms to reach the structure interface. On the other hand, innovative freeform mirrors proved necessary to meet the requirements of compactness and optical performance; freeform surfaces can be defined as surfaces with no axis of rotational invariance, within or beyond the optical part [10]. In size of 50 to 200mm, the MicroCarb mirrors have high freeform amplitude ranging from 100 to $1000 \mu \mathrm{m}$ PV.

\subsection{Manufacturing}

Starting from a premix (a homogeneous mixture of fine-grained SiC powder, sintering aids and temporary binders), the manufacturing process includes the following sequence of main steps:

1. Cold Isostatic Pressing (CIP) blocks,

2. Green Machining (near-net shaping) with 5-axis milling machines, from pressed blocks,

3. Sintering around $2100^{\circ} \mathrm{C}$, under a protective atmosphere,

4. Precise Grinding of all interfaces and mirror optical faces to be polished,

5. Accurate lapping of the interfaces,

6. Measurements with Coordinate Measuring Machine (CMM),

7. Non-Destructive check with help of a fluorescent dye-penetrant to ensure crack-free parts,

8. Optionally, mechanical proof-testing,

9. Cleaning.

In the present case of MicroCarb, the optical faces of the mirrors were then coated with R-SiC polishing layer and polished by Safran-Reosc [11].

The main MicroCarb challenge was to manufacture the complex 3D-shaped structures and mirror sintered blanks but also to grind their interfaces afterwards. It was also primarily a matter of grinding the freeform optical surfaces of the mirrors with great precision and free of surface defects such as steps or striae. The precision and quality of the ground optical surfaces is indeed essential as it will save days or even weeks of polishing, thus directly impacting the cost and the schedule of the project. These challenges have been met by Mersen Boostec thanks in particular to the use of a new, highly precise 5-axis grinding machine and the development of specific grinding processes with it.

The freeform MicroCarb mirrors have been successfully ground with shape deviations in the range of only $10 \mu \mathrm{m}$ PV and free of surface defects. 
The following figures 2 and 3 show two different MicroCarb parts made of Boostec ${ }^{\circledR} \mathrm{SiC}$ material. The figures 4 and 5 show the ongoing integration of the Spectro and the Telescope structures in a clean room at Airbus Defence and Space.

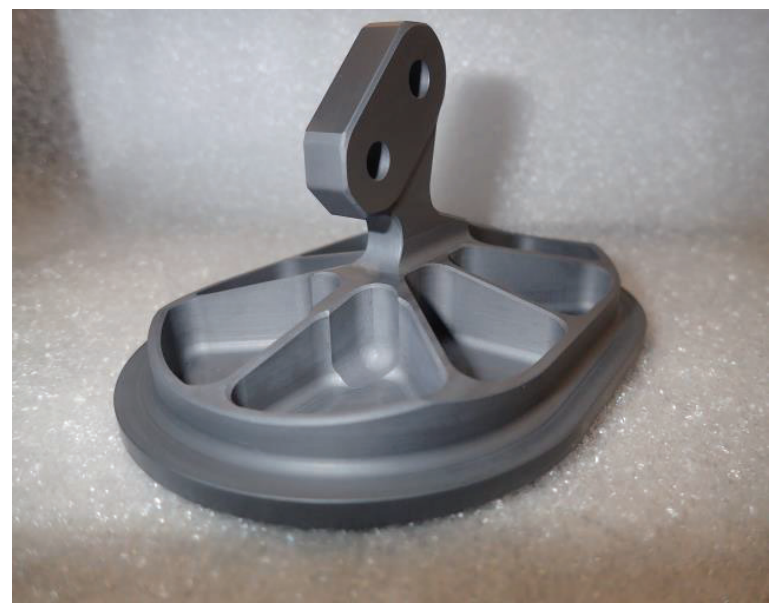

Figure 2. Pointing Mirror (PCS) interface and rear side

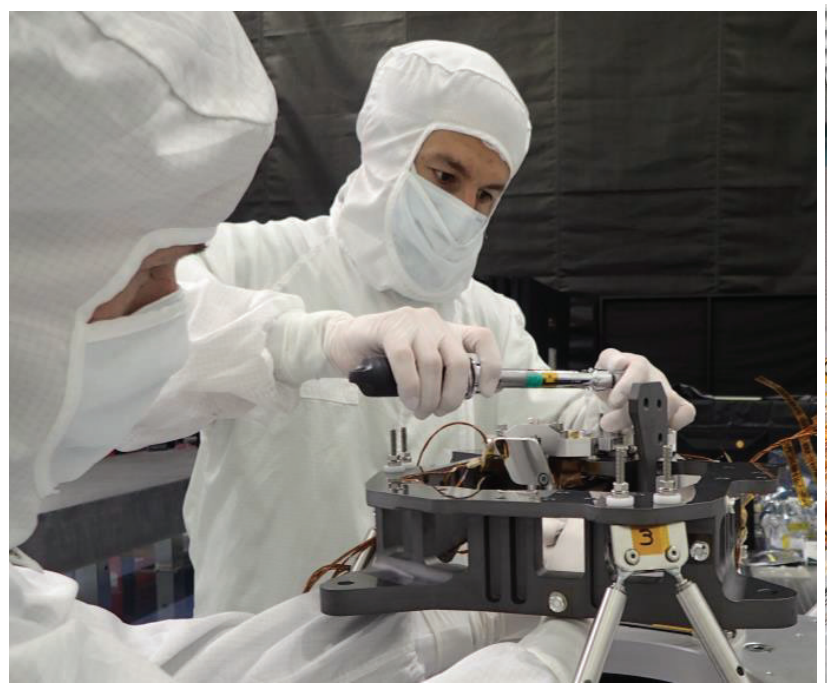

Figure 4. Mounting the mirrors on the $\mathrm{SiC}$ Spectro structure

(C) credit: credit: Airbus Defence and Space

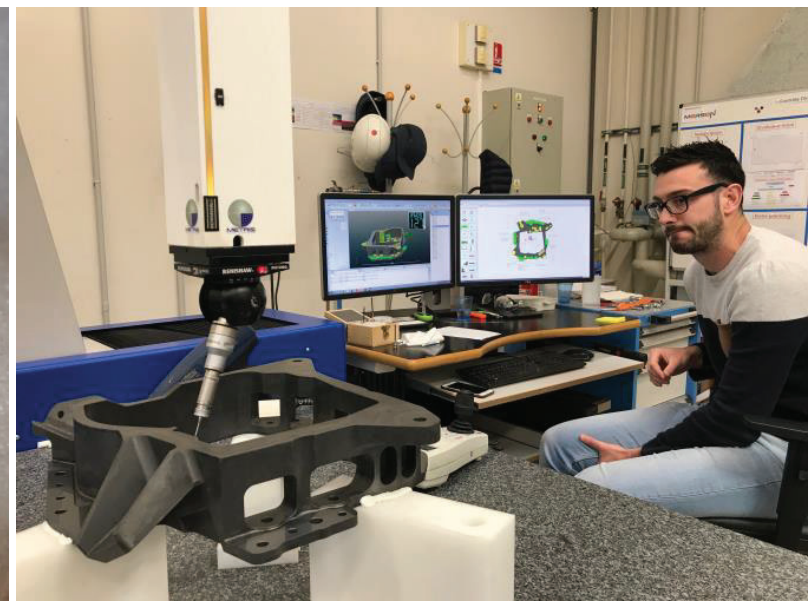

Figure 3. Spectro structure element being measured with CMM

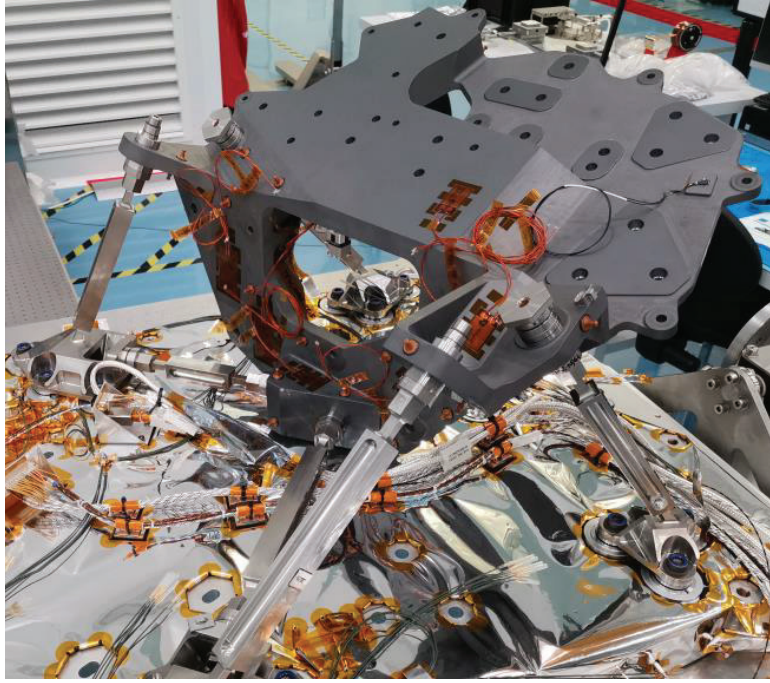

Figure 5. SiC Structure of the Telescope mounted on the instrument baseplate (C) credit: Airbus Defence and Space

\section{CONCLUSION}

As part of the MicroCarb project, Mersen Boostec manufactured complex three-dimensional SiC parts, commissioned a high precision 5-axis grinding machine and successfully developed specific precision grinding processes especially for freeform mirror faces.

With the success of the MicroCarb project, Mersen Boostec has taken an important step forward in the production of complex parts to space standards and of freeform mirrors ready for polishing with precise shape, thereby considerably reducing polishing time and cost.

In 2022, MicroCarb will join the 20 full-SiC telescopes that are already operational in space, for Institutional Sciences of the Universe and for Earth Observation. 


\section{REFERENCES}

[1] Bougoin, M., Castel, D., Levallois, F., "CTE homogeneity, isotropy and reproducibility in large parts made of sintered SiC", Proc. SPIE 10564, International Conference on Space Optics — ICSO 2012, 1056410 (20 November 2017)

[2] Bougoin, M., Lavenac, J., " From Herschel to GAIA, 3m-class SiC space optics », Proceedings of SPIE, The International Society for Optical Engineering, Optical Manufacturing and Testing IX, San Diego, California, United States, August 2011, vol. 8126

[3] Bougoin, M., "SiC challenging parts for GAIA", Proc. SPIE 10565, International Conference on Space Optics — ICSO 2010, 105652C (20 November 2017)

[4] Breysse, J., Castel, D., Bougoin, M., "All-SiC telescope technology at EADS-Astrium - Big step forward for space optical payloads", Proc. SPIE 10564, International Conference on Space Optics — ICSO 2012, 1056442 (30 August 2019)

[5] Bougoin, M., Mallet, F., Lavenac, J., Gerbert-Gaillard, A., Ballhause, D., Chaumeil, F., « Full-SiC EUCLID’s very large teslescope", Proc. SPIE 11180, International Conference on Space Optics — ICSO 2018, 111801P (12 July 2019)

[6] Racca, G.D., Laureijs, R., Stagnaro, L., Salvignol, J.-C., Alvarez, Criado, G. S., et al., "The Euclid mission design", Proc. SPIE 9904, Space Telescopes and Instrumentation 2016: Optical, Infrared, and Millimeter Wave, 990400 (19 July 2016)

[7] MicroCarb (Carbon Dioxide Monitoring Mission), eoPortal Directory, Satellite Missions, https://directory.eoportal.org/web/eoportal/satellite-missions/m/microcarb

[8] Buisson, F., "An updated status of MicroCarb project”, IWGGMS-14 Toronto 8-10 May 2018

[9] Pasternak, F., Bernard, P., Georges, L., Pascal, V., "The Microcarb instrument", Proc. SPIE 10562, International Conference on Space Optics - ICSO 2016, 105621P (25 September 2017)

[10] Rolland, J. P., Davies, M. A., Suleski, T. J., Evans, C., Bauer, A., Lambropoulos, J. C., Falaggis, K., « Freeform optics for imaging", Optica Vol. 8, Issue2, pp.161-176 (2021)

[11] Geyl, R., Ruch, E., Bourgois, R., Mercier-Ytier, R., Leplan, H., Riguet, F., "Freeform optics design, fabrication and testing technologies for Space applications", Proc. SPIE 11180, International Conference on Space Optics ICSO 2018, 111800P (12 July 2019); 